\title{
BMJ Open Identifying research priorities in newborn medicine: a Delphi study of parents' views
}

\author{
Abbey L Eeles (D) ,1,2,3,4 Alice C Burnett, ${ }^{1,2,5,6}$ Jeanie LY Cheong (D) , ${ }^{1,7,8}$ Alex Aldis, ${ }^{9}$ \\ Louise Pallot, ${ }^{9}$ Tien Polonidis, ${ }^{9}$ Krista Rust, ${ }^{9}$ Rod W Hunt, ${ }^{1,4,5,6}$ Clare Delany, ${ }^{10,11}$ \\ Alicia J Spittle, ${ }^{1,3,8}$ The Centre of Research Excellence in Newborn Medicine
}

To cite: Eeles AL, Burnett AC, Cheong JLY, et al. Identifying research priorities in newborn medicine: a Delphi study of parents' views. BMJ Open 2021;11:e044836. doi:10.1136/ bmjopen-2020-044836

- Prepublication history and additional supplemental material for this paper are available online. To view these files, please visit the journal online (http://dx.doi.org/10.1136/ bmjopen-2020-044836)

ALE and ACB are joint first authors.

Received 15 September 2020 Accepted 15 October 2021

Check for updates

(C) Author(s) (or their employer(s)) 2021. Re-use permitted under CC BY-NC. No commercial re-use. See rights and permissions. Published by BMJ.

For numbered affiliations see end of article.

Correspondence to

Dr Abbey L Eeles;

abbey.eeles@mcri.edu.au

\section{ABSTRACT}

Objective Neonatal conditions can have lifelong implications for the health and well-being of children and families. Traditionally, parents and patients have not been included in shaping the agenda for research and yet they are profoundly affected by the neonatal experience and its consequences. This study aimed to identify consensus research priorities among parents/patients of newborn medicine in Australia and New Zealand.

Design Parents/patients with experience of neonatal care in Australia and New Zealand completed an online Delphi study to identify research priorities across four epochs (neonatal admission, early childhood, childhood/ adolescence and adulthood). Parents/patients first generated key challenges in each of these epochs. Through inductive thematic analysis, recurring topics were identified and research questions generated. Parents/ patients rated these questions in terms of priorities and a list of questions consistently rated as high priority was identified.

Participants 393 individuals participated, 388 parents whose children had received neonatal care and 5 adults who had received neonatal care themselves.

Results Many research questions were identified as high-priority across the lifespan. These included how to best support parental mental health, relationships between parents and neonatal clinical staff (including involvement in care and communication), bonding and the parent-child relationship, improving neonatal medical care and addressing long-term impacts on child health and neurodevelopment.

Conclusions Parents with experience of newborn medicine have strong, clear and recurring research priorities spanning neonatal care practices, psychological and other impacts on families, and impacts on child development. These findings should guide neonatal research efforts. In addition to generating new knowledge, improved translation of existing evidence to parents is also needed.

Preterm birth (<37 weeks' gestation) and serious neonatal conditions, such as major congenital abnormalities, typically require urgent neonatal hospitalisation and critical care, and can have lifelong consequences for the babies and their

\section{Strengths and limitations of this study}

- Participants in the study were experts in newborn medicine by virtue of their lived experience (adults whose children received this care or adults who received neonatal intensive or special care).

- The study involved extensive parent/patient engagement from its methodological design to the interpretation and dissemination of the findings.

- A three round electronic Delphi survey was used to identify consensus research priorities among parents/patients of newborn medicine in Australia and New Zealand.

- We took a holistic, lifespan perspective, inviting parents/patients to identify research priorities across different time points, from the neonatal period to adult life.

- Participants were predominantly mothers (university educated) of children born preterm.

- The priorities identified may not reflect the experiences of the wider family unit, including fathers and partners, or the experiences of patients themselves or people with lower socioeconomic status.

families. In Australia, $18 \%$ of liveborn babies require care in a neonatal intensive care unit or special care nursery (NICU/ SCN). ${ }^{1}$ Significant research efforts are directed towards diagnosis of these conditions, improvements to procedural care and clinical outcomes. However, the topics researched are almost exclusively directed by researchers and clinicians, and there is a growing awareness that the views of parents of patients or adults who have experienced time in NICU have not been sufficiently understood or incorporated into research strategy. ${ }^{2}$ Parent/patient involvement can improve the quality and impact of research by using the unique expert knowledge acquired through lived experience, which is unlikely to be represented by other stakeholders. ${ }^{3}$ Parent/ patient involvement also recognises their 
inherent right to contribute to research directions and methods. ${ }^{4}$

Existing studies involving parent/patient research in newborn medicine have restricted their scope to specific time periods, such as pregnancy and the neonatal period $^{5-7}$ or childhood, ${ }^{8}$ and/or to specific questions, such as interventions and treatments ${ }^{6}$ or defining a core outcome set for neonatal research studies. ${ }^{9}$ While parent/ patient priorities have been reported separately from those of other stakeholders in these studies, sampling only parents/patients is likely to have the least risk of authority bias on the opinions expressed. In studies focusing on the antenatal and neonatal periods, families have highlighted prevention and prediction of preterm birth, care of mothers, psychosocial support for families during and after hospital admission, treatments for newborn medical complications, infant feeding and the presence of health inequities as high priorities. ${ }^{5-7}$ Parents / patients also highlight the following outcome measures as their priorities for any research study: rates of survival, major medical complications or conditions, healthcare-related adverse events, pain and suffering, as well as impacts on the parent-infant relationship. ${ }^{9}$ When parents/patients were asked to consider the childhood period, education, socialemotional outcomes and parental well-being emerged as high priorities. ${ }^{8}$ These studies represent important early advances in understanding what research domains are important to parents/patients in newborn medicine. However, these parent/patient views were collected together with clinician/researcher views, which may have introduced authority bias. There remains a need to listen to the independent perspective of parents and patients in generating and prioritising areas of research and to take a holistic, lifespan perspective that acknowledges the potential for priorities to evolve across time. Therefore, this study aimed to identify consensus research priorities for newborn medicine among parents/patients, with an explicit focus on independent parent/patient-generated priorities from the neonatal period to adult life.

\section{METHODS}

\section{Design and participants}

This study used an electronic Delphi survey, a wellestablished method for enabling a group of experts to address a complex problem and reach consensus. ${ }^{10}$ The Delphi method involves asking experts recurring questions through a series of surveys. Experts receive feedback of group responses and can then modify their response while maintaining anonymity, which is intended to eliminate potential sources of conflict and bias around expressing divergent opinions. ${ }^{11} 12$ A three-round survey was used in this study as this is the minimum number recommended to generate consensus ${ }^{13}$ and additional rounds produce minimal change in group consensus. ${ }^{10}$ To avoid bias in the consensus-building process, the round 3 survey was only sent to participants who responded in round 2.
In this study, participants were considered to be experts in newborn medicine by virtue of their lived experience as parents whose children received neonatal care or adults who as babies, received this care themselves in Australia or New Zealand. Based on the American Academy of Pediatrics levels of neonatal care, ${ }^{14}$ a NICU in Australia or New Zealand is the equivalent of a level III or IV, whereas a SCN would be defined as a level I or II. Eligibility criteria included survey respondents being 18 years of age or older, reading and writing in English, either independently or with the assistance of a family member, friend or colleague, and identifying as a parent of someone who was admitted to a NICU or SCN or identifying as a person who was admitted to a NICU or SCN as a baby. Participants were recruited on the basis of having some experience of NICU or SCN. This sampling approach was deliberately broad to capture people motivated to discuss their experience whether recent or in the past. This sampling technique aimed to enhance the likelihood that participants would be willing to engage with the Delphi process rather than aim for generalisable data or results based on a particular type of participant sample. Participants were recruited over 2 weeks from September 2019 using social media pages and websites of the Centre for Research Excellence (CRE) in Newborn Medicine, Murdoch Children's Research Institute and parent support groups for preterm and sick newborns in Australia and New Zealand. 'Snowballing' recruitment was also used, whereby participants and members of the CRE in Newborn Medicine Consumer Advisory Group (CAG) were encouraged to share the study with their networks. Members of the CAG who were involved in data analysis, outlined below, were excluded from participation.

\section{Patient and public involvement}

During the CRE in Newborn Medicine's quarterly CAG meeting, members, all of whom are past patients of neonatal care, either as a parent of a baby who required neonatal care or as an adult who received neonatal care themselves, brainstormed and revised the research question and initial Delphi survey design. Further patient involvement occurred by way of the CRE CAG members refining the participant information statement and improving the appropriateness and wording of other research documents (ie, the online invitation to participate and social media copy), assisting with recruitment to the study by sharing the participation link with their networks, assisting with the analysis of qualitative data and preparing and revising the study manuscript. Results of the current study will be shared with participants through email and will include a link to the published article, a plain language summary and a short video abstract from the research team providing a summary of the results.

\section{Delphi survey process}

Survey data were collected and managed using secure Research Electronic Data Capture (REDCap) tools ${ }^{15} 16$ hosted at the Murdoch Children's Research Institute. Data 


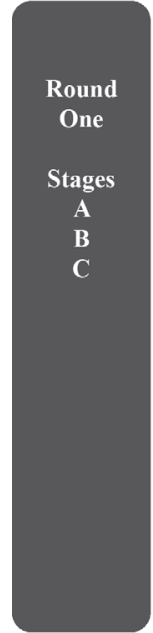

393 consumers consented

*293 provided a response to at least one "problem or challenge" question

*100 provided data confirming eligibility

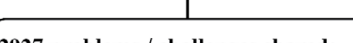

2927 problems / challenges shared:

1299 Neonatal; 909 Early Childhood; 450 School-age; 243 Adult life; 26 Other

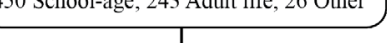

Thematic analysis. Inductive coding approach generated 225 recuring themes

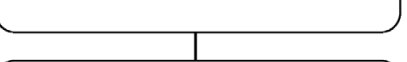

Themes organised and converted into 38 research questions: 13 Neonatal; 14 Early Childhood; 7 School-age; 4 Adult life

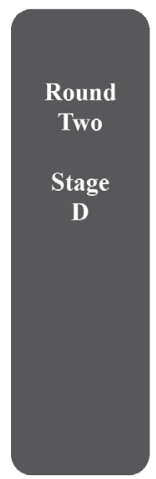

38 research questions emailed to 393 consumers

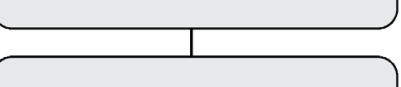

230 consumers ranked research questions in terms of perceived priority:

1 , very low, 7 , very high

4 research questions reached High Priority \& High Consensus rating and placed on a final priority list
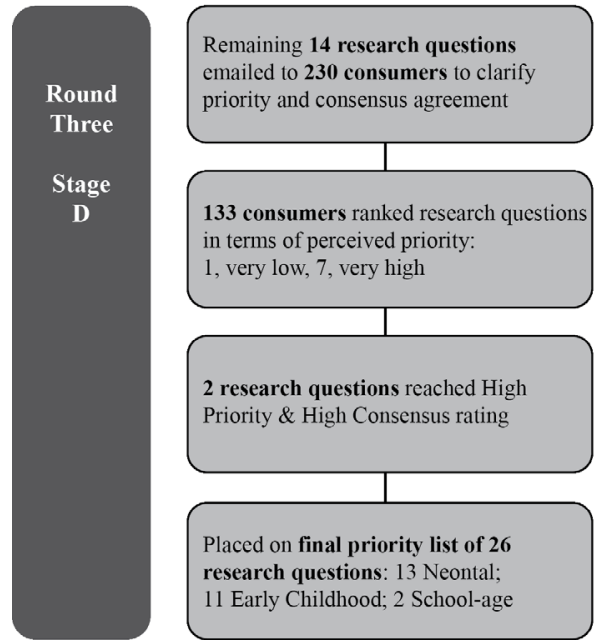

Figure 1 Delphi survey process

collection and analysis and the development of the Delphi survey encompassed the following stages: (A) identifying broad problem areas that parents/patients considered were important areas for future research; (B) qualitatively analysing problem areas and identifying recurring themes; (C) organising and converting recurring themes into research questions and (D) rating and prioritising research questions. Figure 1 details the process followed. The three-round Delphi survey and its corresponding stages are described below.

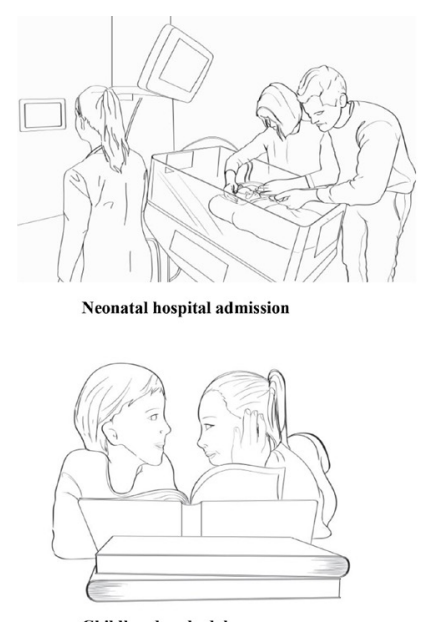

Childhood and adolescence
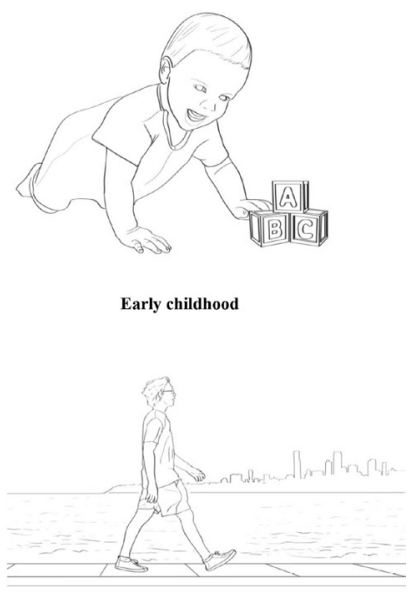

Adult life

Figure 2 Black and white line drawings accompanying the different epochs

Round 1 (stages A-C). The purpose of round 1 was to collect basic demographic data and gather the expertise of parents/patients through identifying areas they consider important for research. In the absence of a clear literature base to develop the survey and to capture a pure representation of parent/patient priorities, we asked open-ended questions, ${ }^{17}$ rather than providing participants with a list of researcher-generated research topics. Participants were asked to 'Please briefly describe up to six problems or challenges associated with premature birth or other newborn conditions in this period' for each of four epochs (the neonatal hospital admission; early childhood; childhood and adolescence; and adult life). Each epoch was accompanied by a black and white line drawing (figure 2) to assist participants' recall and conceptualisation of their concerns. ${ }^{18}$ Black and white line drawings were used as opposed to photographs or colour drawings to assist participants to visualise and recall a specific epoch but without eliciting an emotional reaction induced by real people and children. ${ }^{19}$ Participants were invited to respond to all epochs if they wished, regardless of their current experience.

Round 1 data were qualitatively analysed using thematic analysis, in order to identify and report patterns (or themes) within the data. All initial data analysis was conducted by authors ALE and ACB using an inductive approach, and independent coding in the form of a code-defining approach was applied to a subset of data to check the quality of the analysis. ${ }^{20}$ Analysis of round 1 data was conducted manually using the steps outlined by Braun and Clarke ${ }^{21}$ and data were managed using QSR International's NVivo V.12 software. ${ }^{22}$ Authors RWH and KR (a senior neonatologist and a member of the CAG, respectively) assisted in reviewing the coding structure to ensure congruence and identify any missing elements. The final identification, naming and definition of themes, based on the initial structured coding, was then organised and converted into a list of research questions and was completed collaboratively by ALE, ACB, AJS, CD, KR and 
RWH. This step involved these authors meeting regularly to review the codes and associated data and to identify research-based questions that accurately captured and could address these concerns.

Round 2 (stage D). The purpose of round 2 was to prioritise the research questions generated from the parent/patient-reported experiences in round 1. Participants were asked to rate the importance of each research question using a seven-point Likert scale (1, very low priority; 7 , very high priority). Median ratings and interquartile ranges were calculated. Questions with a median score of 6 or 7 and an IQR of 1 or less were considered to be 'high priority' and 'high consensus' (ie, $75 \%$ or more of the sample agreeing the priority level is a 'fairly high' or higher priority) and were included in the priority list.

Round 3 (stage D). The purpose of round 3 was to prioritise research questions that did not reach the high priority-high consensus threshold in round 2 . The same seven-point Likert scale was used and participants received feedback about ratings from the wider sample. All questions that reached high-priority consensus were added to the final research priority list, and those that did not were excluded. Illustrative quotations were selected from one of the recurring themes within each priority area. ${ }^{23}$

Participants' consent was implied by completing online registration to the round 1 survey, which is standard procedure.

\section{RESULTS}

\section{Sample characteristics}

The overall sample included 393 participants. Participants were predominantly parents whose babies had been admitted to NICU or SCN (n=388, 99\%). Five participants were adults who required a neonatal unit admission at birth. Due to the sample being predominantly parents and for the sake of brevity, hereinafter, we will use the term parents when referring to the participants in our study and describing the results, which is inclusive of the small number $(n=5)$ of people who identified as adults who had experienced neonatal care at birth. Sample characteristics are reported in table 1 . The most frequent reason for NICU/SCN admission was preterm birth and the mean gestational age of those infants was 30.3 weeks (SD 3.6). Participants were predominantly from Australia, female and university educated. Three-quarters of participants identified the neonatal or early childhood periods as closest to their current experience.

\section{Round 1}

In round 1, 293 of 393 (75\%) participants gave 2927 responses regarding problems and challenges, from which 225 recurring themes were coded (figure 1). Key concerns raised in the neonatal period were; parents' mental health and factors such as separation from their child, a lack of involvement in their child's care and ensuring systems of care explicitly included practical
Table 1 Sample characteristics

Total n (\%)

\begin{tabular}{|c|c|c|}
\hline \multirow{2}{*}{$\begin{array}{l}\text { Location of } \\
\text { hospitalisation }\end{array}$} & Australia & $262(67)$ \\
\hline & New Zealand & $131(33)$ \\
\hline \multirow{3}{*}{$\begin{array}{l}\text { Level of care first } \\
\text { admitted to }\end{array}$} & $\mathrm{NICU}$ & 296/388 (76) \\
\hline & $\mathrm{SCN}$ & $90(23)$ \\
\hline & Not sure & $2(1)$ \\
\hline \multirow{4}{*}{$\begin{array}{l}\text { Main reason for } \\
\text { admission }\end{array}$} & Preterm birth & $306 / 388(79)$ \\
\hline & $\begin{array}{l}\text { Surgery for congenital } \\
\text { abnormality }\end{array}$ & $12(3)$ \\
\hline & $\begin{array}{l}\text { Full-term but infection/ } \\
\text { sick }\end{array}$ & $49(13)$ \\
\hline & Another reason & $21(5)$ \\
\hline \multirow[t]{3}{*}{ Sex } & Female & $313 / 388(81)$ \\
\hline & Male & $74(19)$ \\
\hline & Other/prefer not to say & $1(0.3)$ \\
\hline \multirow[t]{5}{*}{ Education } & $\begin{array}{l}\text { Left school }<16 \text { years of } \\
\text { age }\end{array}$ & 9/375 (2) \\
\hline & $\begin{array}{l}\text { Finished year } 11 \text { (second } \\
\text { last year of high school) }\end{array}$ & $11(3)$ \\
\hline & High school certificate & $51(14)$ \\
\hline & University degree & $241(64)$ \\
\hline & TAFE/trade qualification & $64(17)$ \\
\hline \multirow{4}{*}{$\begin{array}{l}\text { Closest epoch } \\
\text { to current } \\
\text { experience }\end{array}$} & Neonatal & $39 / 238(16)$ \\
\hline & Early childhood & $137 / 238(58)$ \\
\hline & $\begin{array}{l}\text { Childhood and } \\
\text { adolescence }\end{array}$ & $51 / 238(21)$ \\
\hline & Adult & $11 / 238(5)$ \\
\hline
\end{tabular}

Denominators vary due to missing data.

.NICU, neonatal intensive care unit; SCN, special care nursery;

TAFE, technical and further education.;

strategies to assist parents to bond with their child. In the early childhood epoch, participating parents highlighted concerns about the type of knowledge they needed to feel confident about supporting their children's health and development and how they can access appropriate healthcare, support services and early interventions. Their own mental health and coping strategies remained a concern. Questions about how their child might be affected developmentally and what resources are required to support recurred in the adolescent and young adult epochs. These themes were organised and converted into 38 research questions. See online supplemental table 1 for the recurring themes identified in each overarching research question.

\section{Rounds 2 and 3}

A total of 230 individuals participated in round 2. Of the 38 research questions, 14 did not reach the high-priority high-consensus threshold and were re-presented in round 3. No questions were rated as a low priority with 
consensus. Of the participants in round 2, 133 (58\%) completed round 3 .

\section{Consensus priorities}

Participants consistently rated 26 research questions as high priority (table 2). No research questions from the adult period reached the high-priority, high-consensus threshold, though all had median rankings of 5 ('fairly high priority') and IQRs of 4-6 (see online supplemental table 2).

\section{DISCUSSION}

Parents of children requiring neonatal care in Australia and New Zealand identified multiple high-priority areas of research in the neonatal, early childhood and childhood/adolescence periods. Top priority areas were mainly in the neonatal epoch and included research into supporting parent mental health, establishing and strengthening partnerships between parents and staff (how parents could be actively included in their babies' care), supporting and nurturing the early parent-infant attachment relationship, and improvements in neonatal medical care. Longer-term priority areas focused on the impacts of neonatal conditions on children's health and development, parent and family well-being, and family resources, as well as the delivery of health and developmental services and information.

The stress and psychological impact of having an infant admitted to a neonatal unit was a recurring and strongly expressed theme in round 1, consistent with empirical data. Anxiety and depression more frequently affect parents of preterm infants compared with parents of healthy term born infants ${ }^{24}$ and symptoms of psychological distress have been shown to persist up to 2 years postbirth. ${ }^{25}$ Furthermore, post-traumatic stress disorder has been reported in up to $41 \%$ of mothers who have had an infant in a NICU, occurring as long as 14 months after their infant's birth. ${ }^{26}$ In the current study, a lack of effective psychological supports available to not only mothers, but fathers and partners, was consistently reported. Understanding and addressing the impact of a neonatal admission on parent mental health is vital as parent mental health problems are associated with poorer child development outcomes. ${ }^{27}$

A key overriding message was the need for clinical staff to engage collaboratively with families in caring for their babies and for hospital systems and procedures to be oriented towards support for families, including minimising separations between parents and infants and managing financial burdens. Parents described that their relationships with clinical staff in the neonatal period encompassed multiple challenges. They reported a lack of inclusion by staff in caring for their babies and a desire to partner with care teams in decision making. Frequently, parents referred to a lack of confidence in caring for their baby, which was interpreted as being exacerbated by the actions of clinical staff. Parents wanted clinical staff to share information about their baby's care and medical status in individualised ways.

These concerns align with the goals and ideals of both family-centred care and family integrated care (FiCare), models of care now supported by many neonatal units around the world. However, implementation and sustainment of evidence-based models of care within the dynamic nature of a healthcare system is challenging and the results of this research highlight that the goals of family-centred care are not yet being achieved in practice, and there remains a need to continue to strive for research agendas and clinical practice which focuses on strategies to improve family centred care in Australian and New Zealand neonatal units. Family-centred care is 'an approach to healthcare that is respectful of and responsive to individual families' needs and values'. ${ }^{28}$ Evidence suggests that programmes that actively integrate parents into the care of their infant and support the parent-infant attachment relationship are associated with improvements in parent well-being and child development outcomes. ${ }^{29}$ Such programmes foster equal partnerships between staff and parents in the neonatal unit $^{30-32}$ and our findings suggest families would be highly supportive of further intervention studies in this area.

A recurring theme in the current study was how physical separation of parents from their babies affected the bonding experience and the parent-infant attachment relationship. Whether through the lack of facilities for parents to stay with their babies, maternal healthcare needs, or the hospital's distance from home and other children, the significant stress associated with this separation warrants attention. Working within units' physical constraints, much can be done to create opportunities for closeness between parents and babies, which supports the development of the parent-infant attachment relationship. These include the consistent and prolonged practice of skin-to-skin kangaroo care, engaging and partnering with parents in everyday care giving, and demonstrating developmentally supportive touch and other sensory experiences such as the use of parental voice.

In addition to the psychological impacts for families, parents also recognised that advances in medical care to prevent and treat neonatal conditions and complications should be a high priority. Parents wanted research into improving management and long-term health outcomes related to specific organ systems such as respiratory and cardiac health, congenital and chromosomal conditions, treatment side effects, infection and other complications. In addition to improvements in neonatal medical care, addressing the feeding information and support needs of families, improving antenatal and postnatal care for mothers, including the consistency and continuity of care, and improving preparation for discharge by giving information and anticipatory guidance about their children's future health and development were high priorities for parents. These findings aligned with previous studies, which have highlighted prevention and prediction of preterm birth, survival, major medical complications or 
Table 2 Consensus research priorities in order of mean ratings within epochs, with illustrative quotations from one of the recurring themes within the overarching research question

\begin{tabular}{|c|c|c|c|c|}
\hline Research questions & Illustrative quotations & Median (IQR) & M (SD) & Overall rank \\
\hline \multicolumn{5}{|l|}{ Neonatal Period } \\
\hline $\begin{array}{l}\text { How can the neonatal } \\
\text { experience affect parents' } \\
\text { mental health and how can } \\
\text { this be improved? }\end{array}$ & $\begin{array}{l}\text { Counselling and support should be offered straight } \\
\text { away. Parents are traumatised and very few } \\
\text { nurses can actually deal with them. I have had a } \\
\text { baby in NICU twice. I had PTSD from the first but } \\
\text { was offered zero support before, during or after. }\end{array}$ & $7(6-7)$ & $6.36(0.84)$ & 1 \\
\hline
\end{tabular}

\begin{tabular}{|c|c|c|c|c|}
\hline $\begin{array}{l}\text { How can hospital systems } \\
\text { and procedures support } \\
\text { families in the neonatal } \\
\text { period? }\end{array}$ & $\begin{array}{l}\text { I think we will look back on this time and consider it } \\
\text { grotesque that we would ask mums to leave babies } \\
\text { behind and drive home each night going against } \\
\text { the power of parental love. }\end{array}$ & $7(6-7)$ & $6.32(0.93)$ & 2 \\
\hline $\begin{array}{l}\text { How can families and health } \\
\text { professionals work together } \\
\text { when babies are in hospital? }\end{array}$ & $\begin{array}{l}\text { The people in SCN are very caring, but you are } \\
\text { made to feel as if you're not needed. You need to } \\
\text { assert yourself to look after your own baby. }\end{array}$ & $7(6-7)$ & $6.31(0.97)$ & 3 \\
\hline
\end{tabular}

How can parents be best $\quad$ Feeling like my baby wasn't my baby and having to 7 (6-7) $6.24(0.97) \quad 4$ supported to bond with their ask permission to touch my baby.

babies?

What is important about staff-parent relationships and interactions during the neonatal period?

\section{How can medical care for babies be improved?}

How can families be supported in practical ways during the neonatal period?

\section{Complacency of staff who work in NICU / that}

is their norm. They work there every day so it's normal for them - it's not normal for a new mum in a NICU so having compassion from staff no matter how Groundhog Day it is, is really important

My daughter had $\mathrm{CHD}$ as well as being prem. This was very hard to deal with, and a challenge for what needed to be prioritised first.

The juggle of my toddler \& unborn child whilst admitted pre birth and again post birth when the baby was in NICU was challenging. My toddler could only come for limited periods to visit \& every time he had to go home whilst I was admitted, we both cried. During an already stressful time, this stress on all of us was really hard.

What information and
support do parents need
about feeding?
How can feelings of
isolation and separation be
understood and improved
for all members of the
family?

How and where should mothers receive postnatal care?

How can healthcare during pregnancy be improved?

\section{The premature feeding process and needs are} different to that of a full term baby initially and there is little knowledge of this, for example, lack of sucking reflex and its consequence on milk or bottle feeding me and our baby. We were airlifted to a city away

from home to have our daughter due to a full NICU

in our home city. We were both traumatised and needed each other and being apart was hard

Little help from staff during postnatal stay. As my

baby was in NICU I was very much left to myself since I was 'well'

Even though I had a high risk pregnancy there really was no education given on what the risks
$6(6-7)$
$6.22(1.01)$
5

My husband wasn't able to stay at the hospital with 6 (5-7)

$6(5-7) \quad 5.87(1.10) \quad 11$ or likelihood my babies would have to spend time in the NICU/SCN and what to expect. It was overwhelming and traumatic.

$6(6-7) \quad 6.17(1.07) \quad 6$

$6(5-7) \quad 5.88(1.08) \quad 10$

$y$


Table 2 Continued

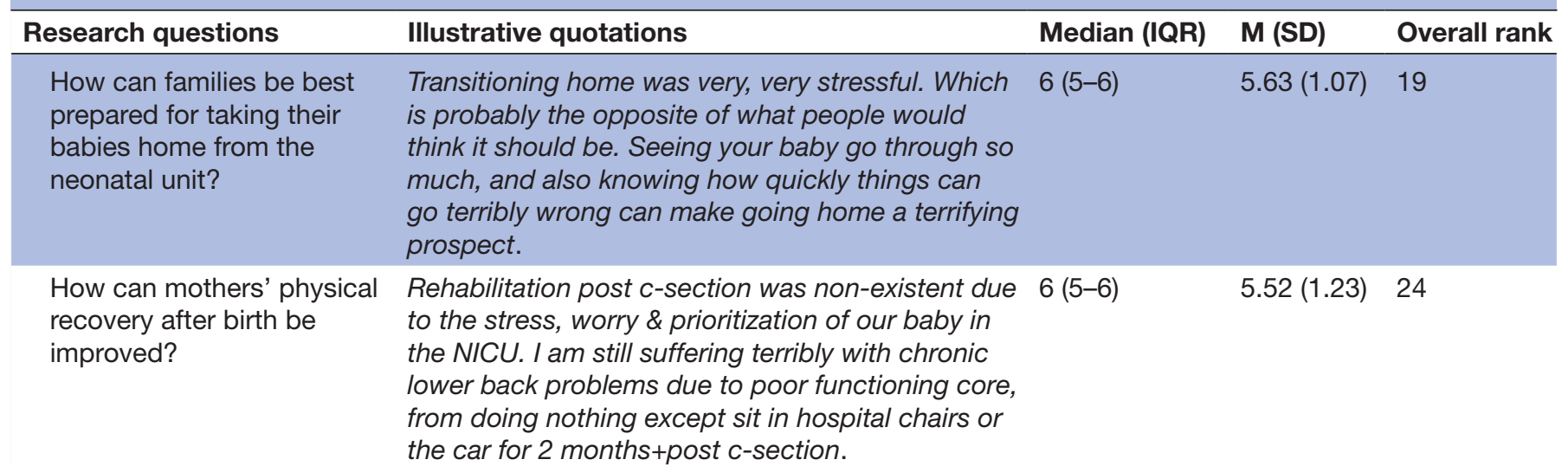

\section{Early Childhood Period}

How can neonatal conditions affect the development of children's skills and abilities and how can this be improved?
Despite regular follow up, it was hard to know if we 6 (6-7)
$6.15(0.96) \quad 7$
should expect any learning difficulties etc as she
progressed through to starting kindergarten. 
Table 2 Continued

\begin{tabular}{|c|c|c|c|c|}
\hline Research questions & Illustrative quotations & Median (IQR) & M (SD) & Overall rank \\
\hline $\begin{array}{l}\text { How can families and health } \\
\text { professionals work as equal } \\
\text { partners in caring for young } \\
\text { children? }\end{array}$ & $\begin{array}{l}\text { When your baby continues to have feeding issues } \\
\text { after leaving hospital and you can't access help you } \\
\text { need as GP, physio, community health nurse, OT } \\
\text { just tell you to discuss it with the paediatrician [and] } \\
\text { once you get an appointment, a parent's concerns } \\
\text { are dismissed. }\end{array}$ & $6(5-6)$ & $5.43(1.03)$ & 26 \\
\hline \multicolumn{5}{|l|}{$\begin{array}{l}\text { Childhood and Adolescent } \\
\text { Period }\end{array}$} \\
\hline $\begin{array}{l}\text { What are the long-term } \\
\text { health and medical impacts } \\
\text { on the child and how can } \\
\text { these be improved? }\end{array}$ & $\begin{array}{l}\text { Health issues arising as a result of being preterm } \\
\text { that were not originally evident. }\end{array}$ & $6(5-7)$ & $5.76(1.08)$ & 16 \\
\hline
\end{tabular}

*Equal ranking

conditions, medical treatments and adverse events, pain and suffering, feeding, the impacts on the parent-infant relationship, and support for families after discharge from hospital as research priorities. ${ }^{569}$

In contrast to previous studies, our study took a lifespan perspective of neonatal conditions, asking parents to consider several epochs. Parents consistently identified child development and parent/family mental health and well-being as priority areas beyond the neonatal period. This is not surprising given that neonatal conditions can have lifelong implications for development. Preterm birth is the most well researched of these neonatal conditions, particularly with respect to longer-term developmental consequences, and was the most frequent condition in our sample. Preterm birth increases the chance of impairments in neurosensory, physical, social-emotional and academic functioning, ${ }^{33-35}$ and around one in two infants born extremely preterm will experience a developmental impairment of varying severity in early childhood. ${ }^{36}$ In addition, preterm birth can have an ongoing negative influence on parent mental health, family functioning ${ }^{25}$ and the parent-infant attachment relationship. ${ }^{37}$ Parents also identified education needs regarding understanding how neonatal conditions can affect development, both for themselves and for community health professionals. In a recent study, which included a relatively small group of parents and patients, education, socialemotional outcomes and parental well-being were high priority areas of research beyond the neonatal period. ${ }^{8}$
Our participants likewise identified knowledge gaps for education providers as a research area, however, this did not reach the high priority-high consensus threshold. This may reflect the fact that our sample predominantly comprised parents whose children were younger than school age.

Previous studies identifying research priorities in neonatal care have generally included a mix of researchers, clinicians and parent participants. These studies have often included research topics drawn from the literature, inherently generated by researchers and clinicians, which introduces an element of bias to parent priorities. Unlike previous studies, our study has adopted the approach of focusing solely on the lifespan research priorities of parents of neonatal care in a large sample size. Our strong inclusion of parents throughout the entire study, from identifying their problems and challenges to rating the research questions that are of greatest importance to them, is a considerable strength of the study.

We acknowledge some limitations of this study and important avenues for future research. There was attrition across the three rounds. However, we retained a large sample in the context of the existing parent/patient literature. ${ }^{689}$ The sample predominantly comprised parents of children born preterm, so we could not examine whether priorities differed between parents and patients (those who had been critically ill as newborns themselves, or between various neonatal conditions). Furthermore, participants were predominantly mothers and a high 
proportion were university educated $(64 \%)$. The priorities identified may therefore not reflect the experiences of the wider family unit, including fathers and partners, or the experiences of parents with lower socioeconomic status. Although all research questions had a median rating of 'fairly high priority' or greater, priority ratings gradually decreased across the epochs and no research questions from the adult period reached the high-priority, high-consensus threshold. Only $1 \%$ of participants were adults who required a neonatal unit admission at birth and three-quarters were parents of infants or young children. Therefore, the lived experience of challenges in adulthood was less represented, which may have contributed to items in this epoch receiving lower ratings. This finding may also reflect a desire for preventative interventions early in life to reduce the frequency and severity of later difficulties. To minimise participant burden, we collected basic demographic data but did not capture ethnicity data. People from a minority or migrant background are likely to experience distinct challenges in engaging with the healthcare system. ${ }^{7}$ Future research is also needed to understand the needs of these and other potentially vulnerable groups of parents and patients.

\section{CONCLUSION}

The public health implications of critical illness in the newborn period are substantial and long-lasting. The identification of a parent-led research agenda provides direction to researchers and clinicians in addressing problems that can translate to more relevant, positive impacts for families who have experienced neonatal care. To maximise these impacts, novel and translational research is needed across development, with a particular focus on parental mental health, collaborative neonatal care, child development and family well-being.

\section{Author affiliations}

${ }^{1}$ Clinical Sciences Theme, Murdoch Childrens Research Institute, Parkville, Victoria, Australia

${ }^{2}$ Newborn Research, The Royal Women's Hospital, Parkville, Victoria, Australia

${ }^{3}$ Department of Physiotherapy, University of Melbourne, Parkville, Victoria, Australia

${ }^{4}$ Department of Paediatrics, Monash University, Clayton, Victoria, Australia

${ }^{5}$ Department of Neonatal Medicine, The Royal Children's Hospital, Parkville, Victoria, Australia

${ }^{6}$ Department of Paediatrics, University of Melbourne, Parkville, Victoria, Australia

${ }^{7}$ Neonatal Services, Royal Women's Hospital, Parkville, Victoria, Australia

${ }^{8}$ Obstetrics and Gynaecology, University of Melbourne, Parkville, Victoria, Australia

${ }^{9}$ Consumer Advisory Group, Murdoch Childrens Research Institute Centre of Research Excellence in Newborn Medicine, Parkville, Victoria, Australia

${ }^{10}$ Children's Bioethics Centre, The Royal Children's Hospital Melbourne, Parkville, Victoria, Australia

${ }^{11}$ Department of Medical Education, University of Melbourne, Parkville, Victoria, Australia

Acknowledgements We would like to acknowledge and thank the following: Ms Renae Allen, Research Coordinator for the Centre of Research Excellence (CRE) in Newborn Medicine, for her invaluable role in the development and establishment of the CRE Consumer Advisory Group and for her administrative support throughout the data collection phase of the study. Dr Sarah McIntyre for her assistance in developing the study research protocol. The members of the CRE in Newborn Medicine Consumer Advisory Group for their input into the study design and materials, assistance with participant recruitment, data analysis and manuscript preparation and revision. The members of the CRE in Newborn Medicine for their support of this study. Chief and associate investigators of the CRE in Newborn Medicine are as follows: Jeanie LY Cheong, Lex W Doyle, Peter G Davis, Peter J Anderson, Alicia J Spittle, Rodney W Hunt, Deanne K Thompson, Katherine J Lee, Brett J Manley, Louise S Owen, Sharon Goldfeld, Gehan Roberts, Susan E Jacobs, Alice C Burnett, Jennifer A Dawson, Rosemarie A Boland, Kim M Dalziel, Karli Treyvaud, Marta Thio, and Alex Aldis. The Life's Little Treasures Foundation, Neonatal Trust, and Miracle Babies Foundation for assistance with participant recruitment and the families who participated in this study.

Contributors ALE and ACB were involved in conception and design of the study, data collection, data analysis and manuscript preparation. JLYC, RWH and AJS were involved in conception and design of the study, and manuscript preparation. AJS was also the guarantor of the study.CD, and Consumer Advisors, LP, TP and $K R$ were involved in design of the study, data collection and interpretation, and manuscript preparation. Consumer advisor, AA was involved in design of the study and manuscript preparation. In addition, all authors provided critical review of the manuscript, approved the final version as submitted, and agree to be accountable for all aspects of the work.

Funding This work was supported by the Australian National Health and Medical Research Council Centre of Research Excellence in Newborn Medicine (GNT 1153176), Career Development Fellowships (1141354 to JC, 1108714 to AJS) and the Victorian Government's Operational Infrastructure Support Programme.

Disclaimer Role of Funder: The funder did not participate in the work.

Competing interests None declared.

Patient consent for publication Not applicable.

Ethics approval This study was approved by the Royal Children's Hospital Human Research Ethics Committee.

Provenance and peer review Not commissioned; externally peer reviewed.

Data availability statement No data are available. The data are not publicly available due to them containing information that could compromise research participant privacy/consent.

Supplemental material This content has been supplied by the author(s). It has not been vetted by BMJ Publishing Group Limited (BMJ) and may not have been peer-reviewed. Any opinions or recommendations discussed are solely those of the author(s) and are not endorsed by BMJ. BMJ disclaims all liability and responsibility arising from any reliance placed on the content. Where the content includes any translated material, BMJ does not warrant the accuracy and reliability of the translations (including but not limited to local regulations, clinical guidelines, terminology, drug names and drug dosages), and is not responsible for any error and/or omissions arising from translation and adaptation or otherwise.

Open access This is an open access article distributed in accordance with the Creative Commons Attribution Non Commercial (CC BY-NC 4.0) license, which permits others to distribute, remix, adapt, build upon this work non-commercially, and license their derivative works on different terms, provided the original work is properly cited, appropriate credit is given, any changes made indicated, and the use is non-commercial. See: http://creativecommons.org/licenses/by-nc/4.0/.

\section{ORCID iDs}

Abbey L Eeles http://orcid.org/0000-0002-2420-8776

Jeanie LY Cheong http://orcid.org/0000-0001-5901-0455

\section{REFERENCES}

1 Australian Institute of Health and Welfare. Australia's mothers and babies 2017 - in brief. Canberra: AlHW, 2019.

2 Ding S, Mew EJ, Chee-A-Tow A, et al. Neurodevelopmental outcome descriptions in cohorts of extremely preterm children. Arch Dis Child Fetal Neonatal Ed 2020;105:510-9.

3 Entwistle VA, Renfrew MJ, Yearley S, et al. Lay perspectives: advantages for health research. BMJ 1998;316:463-6.

4 Staley K. Exploring impact: public involvement in NHS, public and social care research. Eastleigh: INVOLVE, 2009.

5 Duley L, Uhm S, Oliver S, et al. Top 15 UK research priorities for preterm birth. Lancet 2014;383:2041-2.

6 Oliver S, Uhm S, Duley L, et al. Top research priorities for preterm birth: results of a prioritisation partnership between people affected by preterm birth and healthcare professionals. BMC Pregnancy Childbirth 2019;19:528. 
7 Franck LS, McLemore MR, Williams S, et al. Research priorities of women at risk for preterm birth: findings and a call to action. BMC Pregnancy Childbirth 2020;20:10.

8 Zeitlin J, Sentenac M, Morgan AS, et al. Priorities for collaborative research using very preterm birth cohorts. Arch Dis Child Fetal Neonatal Ed 2020;105:538-44.

9 Webbe JWH, Duffy JMN, Afonso E, et al. Core outcomes in neonatology: development of a core outcome set for neonata research. Arch Dis Child Fetal Neonatal Ed 2020;105:425-31.

10 Okoli C, Pawlowski SD. The Delphi method as a research tool: an example, design considerations and applications. Inf Manage 2004;42:15-29.

11 Vernon W. The Delphi technique: a review. Int J Ther Rehabil 2009;16:69-76.

12 Guise J-M, O'Haire C, McPheeters M, et al. A practice-based tool for engaging stakeholders in future research: a synthesis of current practices. J Clin Epidemiol 2013;66:666-74.

13 Iqbal S, Pipon-Young L. The Delphi method. Psychologist 2009;22:598-601 https://www.researchgate.net/publication/ 289089893_The_Delphi_method

14 American Academy of Pediatrics Committee on Fetus And Newborn. Levels of neonatal care. Pediatrics 2012;130:587-97.

15 Harris PA, Taylor R, Minor BL, et al. The redcap consortium: building an international community of software platform partners. J Biomed Inform 2019;95:103208

16 Harris PA, Taylor R, Thielke R, et al. Research electronic data capture (REDCap)--a metadata-driven methodology and workflow process for providing translational research informatics support. J Biomed Inform 2009;42:377-81.

17 Mclntyre S, Novak I, Cusick A. Consensus research priorities for cerebral palsy: a delphi survey of consumers, researchers, and clinicians. Dev Med Child Neurol 2010;52:270-5.

18 Cristancho S, Bidinosti S, Lingard L, et al. Seeing in different ways: introducing "rich pictures" in the study of expert judgment. Qual Health Res 2015;25:713-25.

19 Glegg SMN. Facilitating interviews in qualitative research with visual tools: a typology. Qual Health Res 2019;29:301-10.

20 King N, Horrocks C. Interviews in qualitative research. London: SAGE Publishing, 2010

21 Braun V, Clarke V. Using thematic analysis in psychology. Qual Res Psychol 2006;3:77-101

22 QSR International Pty Ltd. NVivo qualitative data analysis software, version 12, 2018. Available: https://www.qsrinternational.com/nvivoqualitative-data-analysis-software/home

23 Anderson C. Presenting and evaluating qualitative research. Am J Pharm Educ 2010;74:141.
24 Pace CC, Spittle AJ, Molesworth CM-L, et al. Evolution of depression and anxiety symptoms in parents of very preterm infants during the newborn period. JAMA Pediatr 2016;170:863-70.

25 Treyvaud K. Parent and family outcomes following very preterm or very low birth weight birth: a review. Semin Fetal Neonatal Med 2014;19:131-5.

26 Kersting A, Dorsch M, Wesselmann U, et al. Maternal posttraumatic stress response after the birth of a very low-birth-weight infant. $J$ Psychosom Res 2004;57:473-6.

27 Treyvaud K, Anderson VA, Lee KJ, et al. Parental mental health and early social-emotional development of children born very preterm. $J$ Pediatr Psychol 2010;35:768-77.

28 Davidson JE, Aslakson RA, Long AC, et al. Guidelines for familycentered care in the neonatal, pediatric, and adult ICU. Crit Care Med 2017:45:103-28.

29 Ding X, Zhu L, Zhang R, et al. Effects of family-centred care interventions on preterm infants and parents in neonatal intensive care units: a systematic review and meta-analysis of randomised controlled trials. Aust Crit Care 2019;32:63-75

30 Ahlqvist-Björkroth S, Boukydis Z, Axelin AM, et al. Close collaboration with Parents ${ }^{\mathrm{TM}}$ intervention to improve parents' psychological well-being and child development: description of the intervention and study protocol. Behav Brain Res 2017;325:303-10.

31 O'Brien K, Robson K, Bracht M, et al. Effectiveness of family integrated care in neonatal intensive care units on infant and parent outcomes: a multicentre, multinational, cluster-randomised controlled trial. Lancet Child Adolesc Health 2018;2:245-54.

32 Fegran L, Helseth S, Slettebø A. Nurses as moral practitioners encountering parents in neonatal intensive care units. Nurs Ethics 2006;13:52-64

33 Anderson P, Doyle LW, Victorian Infant Collaborative Study Group. Neurobehavioral outcomes of school-age children born extremely low birth weight or very preterm in the 1990s. JAMA 2003;289:3264-72.

34 Johnson S, Marlow N. Growing up after extremely preterm birth: lifespan mental health outcomes. Semin Fetal Neonatal Med 2014:19:97-104.

35 Spittle AJ, Treyvaud K, Doyle LW, et al. Early emergence of behavior and social-emotional problems in very preterm infants. J Am Acad Child Adolesc Psychiatry 2009;48:909-18.

36 Doyle LW, Roberts G, Anderson PJ, et al. Outcomes at age 2 years of infants < 28 weeks' gestational age born in Victoria in 2005. J Pediatr 2010;156:49-53.

37 Borghini A, Pierrehumbert B, Miljkovitch R, et al. Mother's attachment representations of their premature infant at 6 and 18 months after birth. Infant Ment Health J 2006;27:494-508. 